Article

\title{
Differential Effects of Exercise on fMRI of the Midbrain Ascending Arousal Network Nuclei in Myalgic Encephalomyelitis/Chronic Fatigue Syndrome (ME/CFS) and Gulf War Illness (GWI) in a Model of Postexertional Malaise (PEM)
}

\author{
James N. Baraniuk*(D), Alison Amar, Haris Pepermitwala and Stuart D. Washington
}

Citation: Baraniuk, J.N.; Amar, A.; Pepermitwala, H.; Washington, S.D. Differential Effects of Exercise on fMRI of the Midbrain Ascending Arousal Network Nuclei in Myalgic Encephalomyelitis/Chronic Fatigue Syndrome (ME/CFS) and Gulf War Illness (GWI) in a Model of

Postexertional Malaise (PEM). Brain Sci. 2022, 12, 78. https://doi.org/ 10.3390/brainsci12010078

Academic Editor: Luigi De Gennaro

Received: 22 November 2021

Accepted: 21 December 2021

Published: 5 January 2022

Publisher's Note: MDPI stays neutral with regard to jurisdictional claims in published maps and institutional affiliations.

Copyright: (C) 2022 by the authors. Licensee MDPI, Basel, Switzerland. This article is an open access article distributed under the terms and conditions of the Creative Commons Attribution (CC BY) license (https:/ / creativecommons.org/licenses/by/ $4.0 /)$.
Department of Medicine, Georgetown University, Washington, DC 20007, USA; aca117@georgetgown.edu (A.A.); hsp9@georgetown.edu (H.P.); sdw4@georgetown.edu (S.D.W.)

* Correspondence: baraniuj@georgetown.edu

\begin{abstract}
Background: Myalgic Encephalomyelitis/Chronic Fatigue Syndrome (ME/CFS), Gulf War Illness (GWI) and control subjects underwent fMRI during difficult cognitive tests performed before and after submaximal exercise provocation (Washington 2020). Exercise caused increased activation in $\mathrm{ME} / \mathrm{CFS}$ but decreased activation for GWI in the dorsal midbrain, left Rolandic operculum and right middle insula. Midbrain and isthmus nuclei participate in threat assessment, attention, cognition, mood, pain, sleep, and autonomic dysfunction. Methods: Activated midbrain nuclei were inferred by a re-analysis of data from 31 control, $36 \mathrm{ME} / \mathrm{CFS}$ and $78 \mathrm{GWI}$ subjects using a seed region approach and the Harvard Ascending Arousal Network. Results: Before exercise, control and GWI subjects showed greater activation during cognition than ME/CFS in the left pedunculotegmental nucleus. Post exercise, ME/CFS subjects showed greater activation than GWI ones for midline periaqueductal gray, dorsal and median raphe, and right midbrain reticular formation, parabrachial complex and locus coeruleus. The change between days (delta) was positive for ME/CFS but negative for GWI, indicating reciprocal patterns of activation. The controls had no changes. Conclusions: Exercise caused the opposite effects with increased activation in ME/CFS but decreased activation in GWI, indicating different pathophysiological responses to exertion and mechanisms of disease. Midbrain and isthmus nuclei contribute to postexertional malaise in ME/CFS and GWI.
\end{abstract}

Keywords: midbrain; postexertional malaise; PEM; arousal; exercise; fMRI; autonomic; postural tachycardia; Myalgic Encephalomyelitis/Chronic Fatigue Syndrome; ME/CFS; Gulf War Illness; GWI

\section{Introduction}

Myalgic Encephalomyelitis/Chronic Fatigue Syndrome (ME/CFS) [1,2] and Gulf War Illness (GWI) [3,4] share features of postexertional malaise (PEM, exertional exhaustion), fatigue that is not relieved by rest, unrefreshing and non-restorative sleep, total body pain and systemic hyperalgesia. ME/CFS has been considered to be a chronic consequence following flu-like epidemics [5], but in general has a sporadic heterogeneous presentation and unknown etiology. The prevalence is about 0.2 to $2 \%$ [6,7]. The 1994 Center for Disease Control criteria ("Fukuda") require moderate-to-severe unremitting fatigue of new onset that persists for longer than 6 months and has no explanation despite appropriate medical investigations and at least four of the following eight ancillary criteria: cognitive complaints regarding short-term memory or concentration, sore throat, sore lymph nodes, myalgia, arthralgia, headaches (including migraine), disordered sleep and postexertional malaise (PEM) [1]. Emphasis has been placed on PEM, the characteristically delayed exacerbation of the entire symptom complex following minimal physical, cognitive or emotional efforts, as a distinguishing feature of ME/CFS $[3,4,7,8]$. 
GWI affects 25 to $32 \%$ of veterans deployed in the 1990-1991 Persian Gulf War. The Centers for Disease Control criteria for Chronic Multisymptom Illness (CMI) require symptoms from at least two of three clusters: general fatigue; mood and cognitive abnormalities; and myalgia/arthralgia (pain) [3]. Mood/cognitive symptoms can range from troubles with sleep to cognitive difficulties, anxiety and depressive mood. An epidemiological comparison of symptoms between deployed and non-deployed Kansas veterans generated a more sensitive set of criteria requiring three of the following six domains: fatigue and sleep; pain; neurological/cognitive/mood; gastrointestinal; respiratory; and skin symptoms [4]. The etiology has been linked to exposures to neurotoxicants that were present in theatre, including organophosphates, carbamates and other pesticides, sarin/cyclosarin nerve agents and pyridostigmine bromide used as prophylactic medication against chemical warfare attacks $[9,10]$. Symptoms are consistent with Chronic Organophosphate-Induced Neuropsychiatric Disorder (COPIND) [11-13]. Psychiatric etiologies have been ruled out [9].

The overlapping symptoms of GWI and ME/CFS have generated unified hypotheses [10]. However, pathophysiological mechanisms and objective findings that can be used for disease diagnosis and the prediction of potential therapies have been more difficult to identify. We approached this problem by developing a two-day submaximal exercise provocation paradigm with symptom, heart rate variability, and functional magnetic resonance imaging to assess PEM and other changes induced by the exertional challenge. In a previous study, we examined blood oxygenation level-dependent (BOLD) activation during a difficult, high-cognitive-load continuous 2-back working memory task and compared pre-exercise and postexercise scans. The control, ME/CFS and GWI groups were equivalent prior to exercise (baseline), but after exercise ME/CFS subjects had a significant increase in blood oxygenation level-dependent (BOLD) activation while GWI participants had a significant decrease in the dorsal midbrain, right middle insula and left Rolandic operculum [14]. The midbrain region of interest extended from the left to right periaqueductal gray (PAG) and to the adjacent right midbrain reticular formation (MRF), inferior colliculus and lateral lemniscus, and caudally to the right lateral isthmus (Figure S1). Because these nuclei have profound influences on threat assessment, pain, negative emotion, attention, wakefulness, and instinctual neurobehaviors, it was of interest to assess the activation of relevant anatomical midbrain nuclei.

In this report, we re-analyze the original BOLD data [14] (Figure S1) using a seed region approach to gain a preliminary understanding of the nuclei that were activated within the midbrain region of interest. The seed regions were selected from the ascending arousal network that was defined from histological sections and diffusion studies of brainstem white matter tracts [14]. BOLD signals in each of the target nuclei were assessed on preexercise and postexercise days. The aim was to identify which midbrain nuclei were affected by exercise in ME/CFS and GWI subjects and to judge effect sizes to guide future confirmatory studies. We propose that affected nuclei may participate in the pathology of postexertional malaise.

\section{Methods}

\subsection{Ethics}

All subjects gave written informed consent to this protocol that was approved by the Georgetown University Institutional Review Board (IRB 2009-229, 2013-0943 and 2015-0579) and Department of Defense Congressionally Directed Medical Research Program (CDMRP) Human Research Program Office (HRPO) (A-15547 and A-18479) and listed in https: / / clinicaltrials.gov (accessed on 21 November 2021) (NCT01291758 and NCT00810225). All clinical investigations were conducted according to the principles expressed in the Declaration of Helsinki. 


\subsection{Demographics}

GWI, ME/CFS and healthy control subjects were recruited to this four-day-long inpatient study in the Clinical Research Unit of the Georgetown-Howard Universities Center for Clinical and Translational Science. Subjects had history and physical examinations to ensure their inclusion by meeting Chronic Multisymptom Illness [3] and Kansas [4] criteria for GWI, Fukuda [1] and Canadian [2] criteria for ME/CFS, confirmation of sedentary lifestyle for control subjects (less than $40 \mathrm{~min}$ of aerobic activity per week) and exclusion because of serious medical or psychiatric conditions such as psychosis [4,15-17]. History of post-traumatic stress disorder (PTSD) [18] or depression [19] were not exclusions unless the subject had been hospitalized in the past 5 years. Subjects completed the Chronic Fatigue Syndrome Symptom Severity [20], SF-36 quality of life [21], Chalder Fatigue [22] and McGill Pain [23] questionnaires and had systemic hyperalgesia tested by dolorimetry [24,25].

Light sensitivity was assessed by comparing scores while looking up at standard hospital ward fluorescent lights turned on or off with curtains shut and background ambient light in the supine position. Sound sensitivity was assessed by dropping a standard hardboard clipboard (\#44292, Item \#1671406, Model \#ST44292-CC, Staples, Inc. Framingham, Massachusetts 01702-4478, U.S.A.) from 3 feet onto a linoleum floor. The sound intensity 6 feet away at the subject's ear was approximately $60 \mathrm{~dB}$ (ambient noise $\sim 35 \mathrm{~dB}$ ) (Physics Toolbox Sensor Suite). Severity was scored using the modified 0-to-20-point anchored ordinal intensity scale of the Gracely Box score [26-28].

\subsection{Exercise Provocation}

Two submaximal bicycle exercise tests were performed $24 \mathrm{~h}$ apart. Subjects cycled for $25 \mathrm{~min}$ at $70 \%$ of their predicted maximum HR (220 minus patient's age), followed by a climb to $85 \%$ maximum HR to reach their anaerobic threshold $[14,26,27,29,30]$. Identical magnetic resonance imaging scans were run before the first and after the second stress tests, which were then contrasted to show the effects of exertion on cognitive tasks.

\subsection{Orthostatic Postural Tachycardia Phenotypes}

Subjects rested in the supine position for $5 \mathrm{~min}$ with continuous measurements of EKG and arm cuff blood pressure every minute. Average recumbent heart rate (HR) was calculated. Subjects stood up and maintained their posture for $5 \mathrm{~min}$. EKG and blood pressure were recorded each minute. The differences between standing HR at each minute and average recumbent $H R$ were calculated $(\Delta \mathrm{HR})$. The procedure was performed at least twice before the first exercise, then $1,3,8$ and $24 \mathrm{~h}$ post exercise. $\Delta \mathrm{HR}$ was used to define Orthostatic status $[26,27]$.

(i) Postural orthostatic tachycardia (POTS) was defined by $\Delta \mathrm{HR} \geq 30$ beats per minute at least 4 time points before exercise and during each postexercise measurement period.

(ii) Stress Test Activated Reversible Tachycardia (START) was defined by a normal $\Delta H R$ before exercise, but at least 2 episodes with $\Delta \mathrm{HR} \geq 30$ beats per minute after exercise. The phenomenon was transient as postural tachycardia returned to normal within 36 to $48 \mathrm{~h}$.

(iii) The normal postural response was defined as Stress Test Originated Phantom Perception (STOPP) based on original findings in GWI $[30,31]$ where $\Delta \mathrm{HR}$ was in the normal range of $12 \pm 5$ beats per minute and never exceeded 30 beats per minute.

\subsection{Verbal Working Memory Task}

Subjects practiced the 0-back and 2-back working memory task in a mock scanner until they felt proficient $[14,30,31]$. In the scanner, subjects viewed an instruction panel stating "REST" for $0.8 \mathrm{~s}$, followed by $19.2 \mathrm{~s}$ of a blank screen. The instruction "0-BACK" was viewed for $0.8 \mathrm{~s}$, followed by $1.2 \mathrm{~s}$ of a blank screen, and then a string of nine pseudorandomized letters (A, B, C, D) were seen for $0.8 \mathrm{~s}$ each, followed by $1.2 \mathrm{~s}$ of a blank screen per letter. Each time they saw a letter, subjects pressed the corresponding button on an MRI compatible fiberoptic four-button box that was used with both hands. After a second "REST" period, 
they saw the instruction "2-BACK" and again viewed a string of nine letters. They had to view and remember the first two letters, then press the button for the first letter when they saw the third letter (i.e., "2 back", 4 s delay). The 2-back task continued for seven responses. This cycle was repeated five times.

\subsection{MRI Data Acquisition, Preprocessing and Analysis}

All structural and functional MRI data were acquired on a Siemens $3 \mathrm{~T}$ Tim Trio scanner located within the Center for Functional and Molecular Imaging at Georgetown University Medical Center equipped using a transmit-receive body coil and a commercial 12-element head coil array as described previously [14,30,31]. Parameters for structural 3D T1-weighted magnetization-prepared rapid acquisition with gradient echo (MPRAGE) images were: $\mathrm{TE}=2.52 \mathrm{~ms}, \mathrm{TR}=1900 \mathrm{~ms}, \mathrm{TI}=900 \mathrm{~ms}$, flip angle $=9, \mathrm{FOV}=250 \mathrm{~mm}, 176$ slices, slice resolution $=1.0 \mathrm{~mm}$ and voxel size $1 \times 1 \times 1 \mathrm{~mm}$. Images were processed in SPM12 [32]. fMRI data consisted of T2*-weighted gradient-echo planar images (EPIs) acquired during the n-back tasks. The EPI data acquisition parameters were: TR/TE $=2500 / 30 \mathrm{~ms}$, flip angle $=90, \mathrm{FoV}=205 \mathrm{~mm}^{2}$, matrix size $=64 \times 64$, number of slices $=47$, and voxel size $=3.2 \mathrm{~mm}^{3}$ (isotropic). Raw EPI data were preprocessed through the default pipeline within the CONN toolbox [33]. Briefly, steps were: (i) slice timing correction, (ii) subject motion estimation and correction, (iii) outlier detection for "scrubbing" based on Artifact Detection Tools, (iv) co-registration with structural data, (v) segmentation and spatial normalization into standard Montreal Neurological Institute (MNI) space [34] and (vi) spatial smoothing with a stationary Gaussian filter with a full width of $6 \mathrm{~mm}$ at half maximum (FWHM). The voxel size was $2.0 \mathrm{~mm}^{3}$ (isotropic) after spatial normalization and conversion to Montreal Neurological Institute (MNI) space.

All within-subject and group-level image analyses were performed using the SPM12 software package [35]. After accounting for magnetic saturation by removing the first 6 scans, a paradigm based on the timing of events in the 2-back task (Figure 1) was applied to preprocessed EPI data to sort individual subject scans into instruction, fixation, 0-back and 2-back bins. In the original analysis, one-sample $t$-tests contrasted the BOLD signals from the 2-back and 0-back scans of each subject and included estimates of the translation $(\mathrm{x}, \mathrm{y}$, and $\mathrm{z})$ and rotation (roll, pitch, and yaw) as covariates of non-interest. The resulting 2-back $>0$-back contrast maps from every subject were sorted into the control, GWI, and $\mathrm{ME} / \mathrm{CFS}$ groups [14].

For this seed region re-analysis, we used the Harvard Ascending Arousal Network atlas [36,37] in the Lead DBS software package [38-40] to define regions of interest (ROI) for midbrain nuclei. The mean BOLD signal for each ROI was extracted from each subject's contrast map, re-centered to a population grand mean of 0 , and the normalized data were analyzed in the MarsBaR 0.44 toolbox [41,42]. The MarsBaR output was the BOLD activation levels for the 2-back>0-back contrast condition in each midbrain nucleus for the control, ME/CFS and GWI groups on the pre- and postexercise days.

Significant differences were determined by analysis of variance (ANOVA) with Tukey Honest Significant Difference or 2-tailed unpaired $t$-test with Bonferroni correction to correct for multiple comparisons, multivariate general linear modeling (mGLM) of relevant demographic and other independent variables, and partial correlation analysis performed in $\mathrm{R}$ and SPSS v27. The mGLM of BOLD activation in each seed region began with disease status (control, ME/CFS, GWI), orthostatic status (START, STOPP, POTS), PTSD and gender as fixed factors with age, BMI and dolorimetry pressure thresholds as independent variables. The results are shown in the Supplementary Online Materials. 

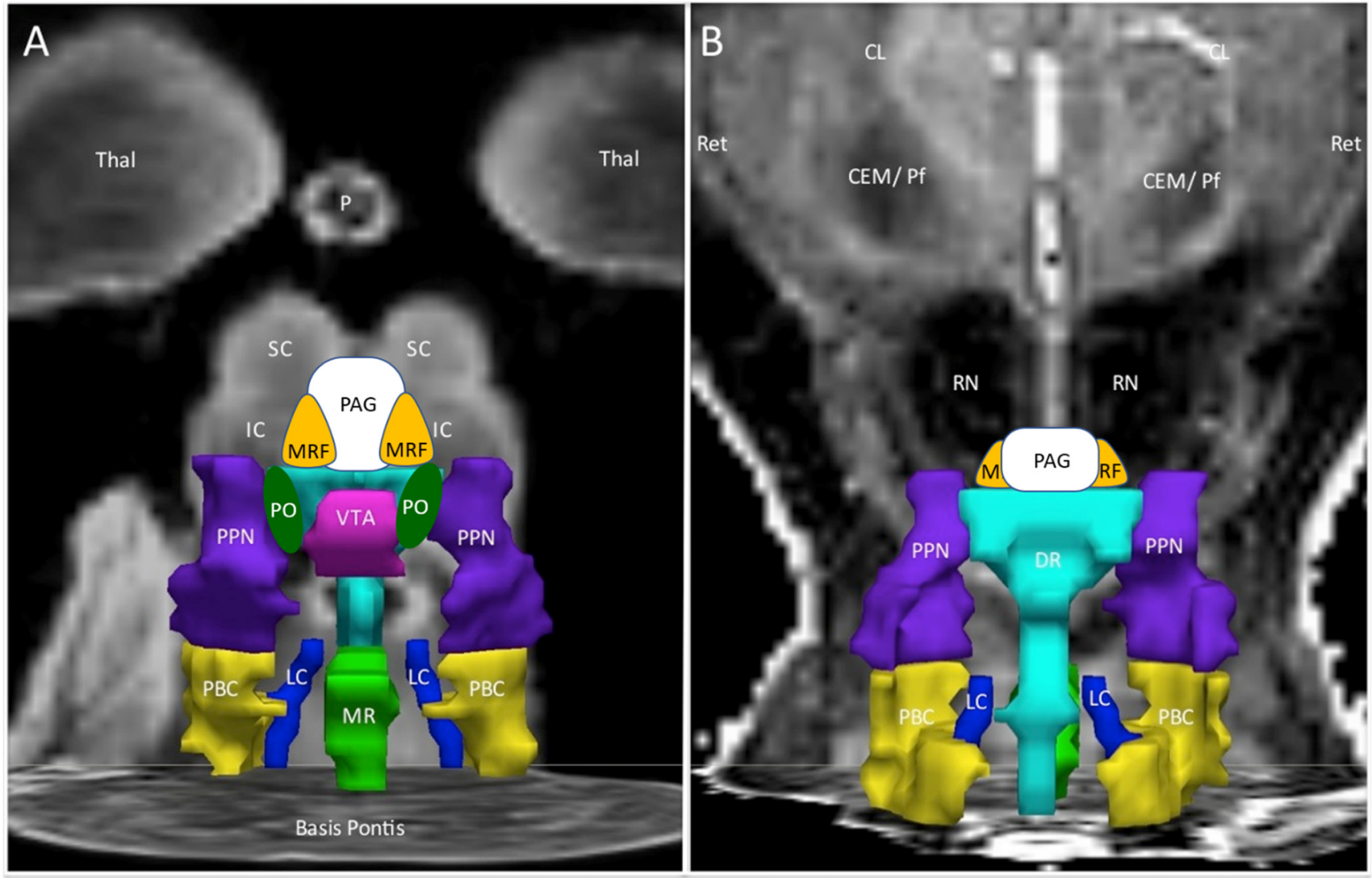

Figure 1. Ascending arousal network. The original figure [37] in the coronal plane was annotated by adding periaqueductal grey (PAG, white), midbrain reticular formation (MRF, orange) and pontis oralis (PO, dark green). (A) The anterior view showed the ventral midbrain with posterior thalamus (Thal) as a "ceiling", the superior (SC) and inferior colliculi (IC) as the backdrop, and Basis Pontis as the "floor". (B) The posterior view of the dorsal midbrain was oriented to show the centromedian/parafascicular nucleus (CEM/Pf), reticular nucleus (Ret), and central lateral nucleus (CL) of the thalamus, pineal $(\mathrm{P})$ and midbrain red nuclei $(\mathrm{RN})$. This depiction suggested three layers with the MRF and PAG being most rostral. The middle layer contained the ventral tegmental area (VTA, violet), bilateral pontis oralis (PO, dark green) and pedunculotegmental nuclei (L and R PTN, formerly pedunculopontine nuclei and labeled PPN in the original image, navy blue) and dorsal raphe (cyan) in the posterior midline. The caudal layer had median raphe (MR, green) and DR flanked by bilateral locus coeruleus (LC, navy blue) and parabrachial complex (PBC, yellow).

Nuclei that were significantly altered based on ANOVA were annotated onto the DBS Harvard anatomical figure (Figure 1, Table 1) [36,37]. When viewed from the anterior (ventral) and posterior (dorsal) sides, the nuclei in the ascending arousal network suggest three layers in the coronal plane of MRI space that approximate their embryological origins [43-45]. Mesomere 1 contributes the superior (SC) and inferior colliculus (IC), midbrain reticular formation (MRF) and periaqueductal grey (PAG). The second layer is derived from rhombomeres 0 and 1 and includes the superior dorsal raphe (DR), pontis oralis (PO), and more lateral pedunculotegmental nuclei (PTN, formerly pedunculopontine nuclei or PPN) [43-45]. The ventral tegmental area (VTA) is anterior when viewed at this level but extends embryologically from the isthmus to diencephalon. The most caudal layer had midline DR and median raphe (MR), and bilateral locus coeruleus (LC) and parabrachial complex (PBC) that are derived from rhombomeres 1 and 2. Embryological origins do not align with the coronal MRI projection because of the marked ventral flexion of the midbrain during the development and distortion of the original neural tube 
structures. Nuclei with significant differences by BOLD were manually highlighted by red outlines using Procreate software.

Table 1. Abbreviations of nuclei in figures.

\begin{tabular}{|c|c|c|}
\hline Abbreviation & Nuclei & Color \\
\hline & Background nuclei for orientation & \multirow{8}{*}{ grey scale } \\
\hline Thal & thalamus & \\
\hline $\mathrm{CEM} / \mathrm{Pf}$ & centromedian/parafascicular nucleus & \\
\hline Ret & reticular nucleus & \\
\hline $\mathrm{CL}$ & central lateral nucleus of the thalamus & \\
\hline $\mathrm{P}$ & pineal & \\
\hline \multirow[t]{2}{*}{$\mathrm{RN}$} & midbrain red nuclei & \\
\hline & Basis Pontis-arbitrary section through the rostral pons to form the "floor" of the figure & \\
\hline & Midbrain and Isthmus (superior to inferior) & \\
\hline SC & superior colliculus & grey \\
\hline $\mathrm{IC}$ & inferior colliculus & grey \\
\hline PAG & periaquequctal grey & white \\
\hline MRF & midbrain reticular formation & orange \\
\hline VTA & ventral tegmental area & violet \\
\hline DR & dorsal raphe & cyan \\
\hline MR & median raphe & lime green \\
\hline PTN & pedunculotegmental nuclei (PTN, formerly PPN pedunculopontine nuclei) & navy blue \\
\hline $\mathrm{PO}$ & pontis oralis & dark green \\
\hline PBC & parabrachial complex & yellow \\
\hline LC & locus coeruleus & royal blue \\
\hline
\end{tabular}

\section{Results}

\subsection{Demographics and Questionnaires}

As expected, there were more females in the ME/CFS group because of the known female predominance [6] and more male veterans in the GWI group from assault divisions deployed to the Persian Gulf (Table 2). PTSD was more common in the GWI subjects. Pressure-induced pain sensitivity tested by dolorimetry was not different because male and female subjects were combined [25]. The ME/CFS and GWI groups had comparable symptom scores that were significantly worse than controls with the exception of pain, SF36 Role Emotional and Mental Health, which indicated more impairment in the GWI group than ME/CFS group.

Pre-exercise BOLD values were assessed by self-reported demographic variables in a multivariable general linear model. The significant covariates were Orthostatic status, low back pain, depression, heart disease, gender and marital status (Table S1). The next iteration used the significant covariates as fixed factors and removed the other variables. Orthostatic status was the only variable to be significant (Table S2).

\subsection{Partial Correlations}

Partial correlations compared BOLD signal intensities for each node on Day 1, Day 2 and the delta with subjective questionnaires about CFS symptoms, SF36 domains, psychological and depression complaints with disease status, orthostatic status, gender, age and BMI as covariates. BOLD data were internally correlated within Day 1, Day 2 and delta, positively correlated between Day 2 and delta, and negatively correlated for Day 1 vs. delta (Tables S3-S6). There were no significant correlations between subjective questionnaire data and objective pre-exercise or postexercise BOLD outcomes. The magnitudes of the significant correlations $(p<0.05$ corrected) were low $(R<0.4$ and $R>-0.4$ for the inversely scored SF36 domains). 
Table 2. Demographics. Questionnaire scores were significantly different between control, ME/CFS and GWI by ANOVA followed by Tukey Honest Significant Difference or Kruskal-Wallis and Mann-Whitney tests ${ }^{*}$ ) corrected for multiple comparisons. Mean $\pm \mathrm{SD}$. (Score ranges).

\begin{tabular}{|c|c|c|c|c|c|c|}
\hline & Control & ME/CFS & GWI & $\begin{array}{l}\text { Control vs. } \\
\text { ME/CFS }\end{array}$ & $\begin{array}{c}\text { Control vs. } \\
\text { GWI }\end{array}$ & $\begin{array}{c}\text { ME/CFS vs. } \\
\text { GWI }\end{array}$ \\
\hline $\mathrm{N}$ & 31 & 36 & 78 & & & \\
\hline Age & $43.2 \pm 16.5$ & $47.3 \pm 13.1$ & $47.1 \pm 7.4$ & & & \\
\hline Female* & $38.7 \%$ & $69.4 \%$ & $21.8 \%$ & 0.029 & & 0.0001 \\
\hline BMI & $28.3 \pm 4.5$ & $26.2 \pm 5.6$ & $29.4 \pm 5.3$ & & & 0.008 \\
\hline Dolorimetry (kg) & $4.6 \pm 2.4$ & $3.9 \pm 1.9$ & $4.2 \pm 2.1$ & & & \\
\hline PTSD * & $9.7 \%$ & $13.8 \%$ & $43.6 \%$ & & 0.001 & 0.004 \\
\hline Migraine * & $13.3 \%$ & $41.7 \%$ & $63.5 \%$ & & $<0.00001$ & \\
\hline $\begin{array}{c}\text { Chalder Fatigue } \\
\quad(0 \text { to } 33)\end{array}$ & $12.3 \pm 5.4$ & $23.3 \pm 6.2$ & $25.3 \pm 4.7$ & $<0.00001$ & $<0.00001$ & \\
\hline $\begin{array}{l}\text { McGill pain } \\
\quad(0 \text { to } 45)\end{array}$ & $3.6 \pm 6.4$ & $13.4 \pm 11.0$ & $23.8 \pm 9.0$ & 0.00012 & $<0.00001$ & $<0.00001$ \\
\hline \multicolumn{7}{|c|}{ CFS Severity Questionnaire (0 no symptom to 4 severe) } \\
\hline Fatigue & $1.3 \pm 1.2$ & $3.4 \pm 0.8$ & $3.5 \pm 0.7$ & $<0.00001$ & $<0.00001$ & \\
\hline $\begin{array}{l}\text { Postexertional } \\
\text { Malaise }\end{array}$ & $0.6 \pm 1.1$ & $3.5 \pm 0.8$ & $3.4 \pm 1.0$ & $<0.00001$ & $<0.00001$ & \\
\hline Sleep & $1.7 \pm 1.4$ & $3.2 \pm 0.9$ & $3.5 \pm 0.8$ & $<0.00001$ & $<0.00001$ & \\
\hline $\begin{array}{c}\text { Memory, } \\
\text { Concentration }\end{array}$ & $1.2 \pm 1.2$ & $2.9 \pm 0.9$ & $3.1 \pm 0.8$ & $<0.00001$ & $<0.00001$ & \\
\hline Muscle Pain & $0.6 \pm 0.9$ & $2.5 \pm 1.3$ & $3.1 \pm 1.0$ & $<0.00001$ & $<0.00001$ & 0.011 \\
\hline Joint Pain & $0.8 \pm 1.0$ & $1.9 \pm 1.4$ & $3.2 \pm 1.0$ & 0.00026 & $<0.00001$ & $<0.00001$ \\
\hline Headache & $1.0 \pm 1.2$ & $2.0 \pm 1.3$ & $2.7 \pm 1.2$ & 0.0022 & $<0.00001$ & 0.025 \\
\hline Sore Throat & $0.3 \pm 0.7$ & $1.0 \pm 1.0$ & $1.4 \pm 1.2$ & 0.031 & 0.000013 & \\
\hline Lymph Nodes & $0.1 \pm 0.4$ & $1.0 \pm 1.1$ & $1.5 \pm 1.3$ & 0.004 & $<0.00001$ & \\
\hline \multicolumn{7}{|c|}{ SF-36 (100 best to 0 worst) } \\
\hline Physical Function & $85.2 \pm 24.2$ & $44.4 \pm 26.5$ & $46.9 \pm 24.6$ & $<0.00001$ & $<0.00001$ & \\
\hline Role Physical & $80.0 \pm 36.8$ & $10.0 \pm 25.9$ & $9.5 \pm 24.8$ & $<0.00001$ & $<0.00001$ & \\
\hline Bodily Pain & $82.9 \pm 20.1$ & $47.2 \pm 27.7$ & $29.5 \pm 18.3$ & $<0.00001$ & $<0.00001$ & 0.00024 \\
\hline General Health & $69.8 \pm 22.8$ & $33.2 \pm 22.9$ & $26.4 \pm 19.2$ & $<0.00001$ & $<0.00001$ & \\
\hline Vitality & $60.2 \pm 20.7$ & $18.0 \pm 15.9$ & $16.6 \pm 15.3$ & $<0.00001$ & $<0.00001$ & \\
\hline Social Function & $80.0 \pm 25.1$ & $30.7 \pm 27.0$ & $30.8 \pm 24.5$ & $<0.00001$ & $<0.00001$ & \\
\hline Role Emotional & $86.7 \pm 31.1$ & $70.5 \pm 44.1$ & $30.7 \pm 38.4$ & & $<0.00001$ & $<0.00001$ \\
\hline Mental Health & $73.6 \pm 16.8$ & $67.8 \pm 17.4$ & $54.8 \pm 22.3$ & & 0.000084 & 0.0056 \\
\hline
\end{tabular}

\subsection{ANOVA}

BOLD data were compared between groups defined by disease status (control, ME/CFS, GWI) and orthostatic status (START, STOPP, POTS) on the pre-exercise and postexercise study days. In the original study, dorsal midbrain activation was not different between groups before exercise [14].

A visual inspection suggested a trend for differences in BOLD between groups. Data from all seed region datapoints and subjects were contrasted between groups. Prior to exercise, the ME/CFS group had numerically lower BOLD values $(0.108 \pm 0.032$, mean $\pm 95 \%$ CI for $\mathrm{n}=504$ datapoints $=$ all regions of interest in all ME/CFS subjects) compared to controls $(0.297 \pm 0.037$, mean $\pm 95 \% \mathrm{CI}, \mathrm{n}=434$ datapoints $)$ and GWI subjects $(0.235 \pm 0.024$, mean $\pm 95 \% C I, n=1092$ datapoints). This suggested reduced blood flow during the 2-back > 0-back condition for ME/CFS at baseline. 
In the ascending arousal network, bilateral PTN, L_PBC, and VTA were significantly more activated in the control group than the ME/CFS group, while the GWI group was higher in L_PTN and L_PO than ME/CFS subjects (Figure 2, Table 3).
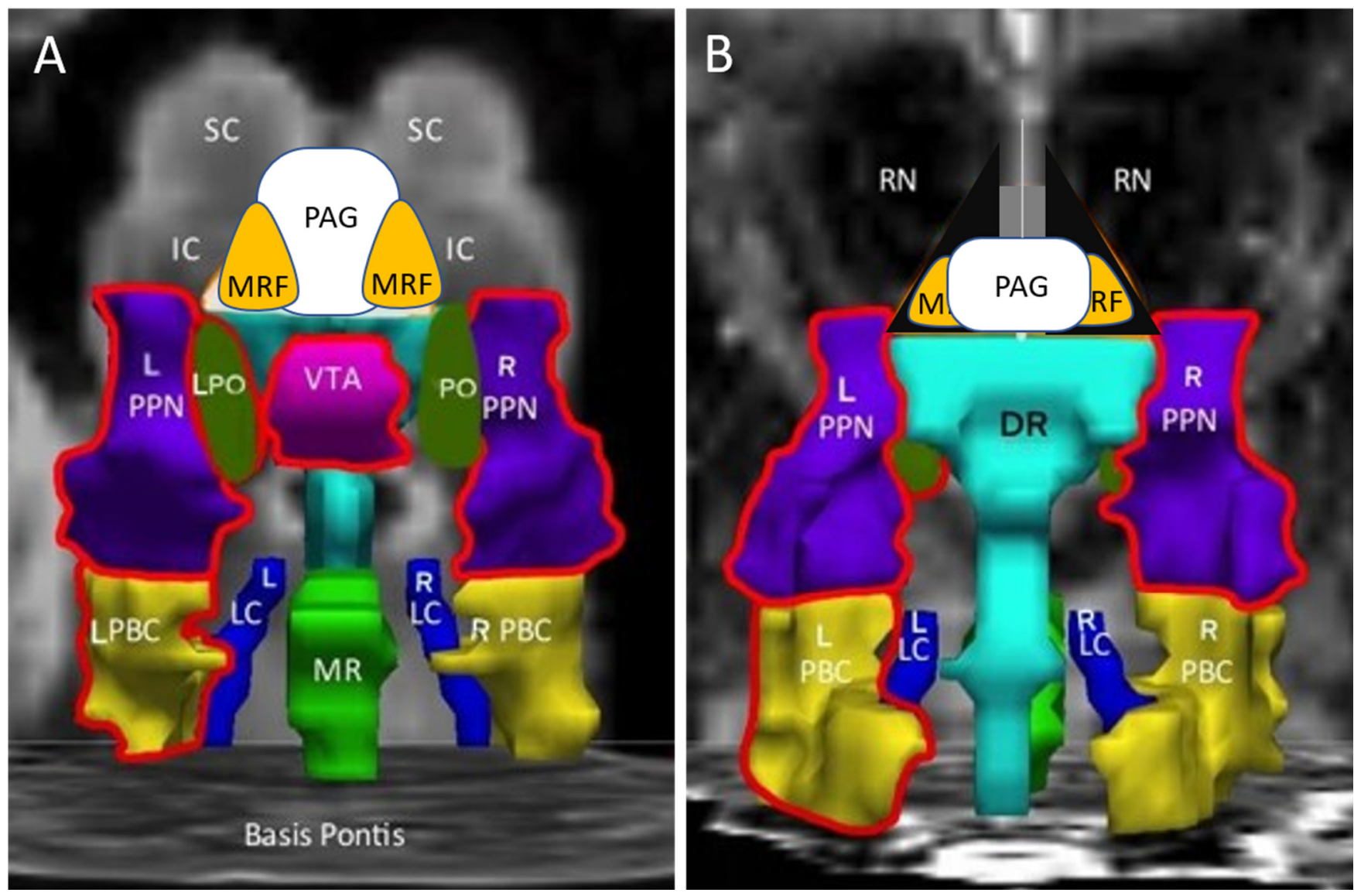

Figure 2. Ascending arousal network before exercise. Nuclei with significantly different levels of activation are highlighted with red in the (A) anterior/ventral and (B) posterior/dorsal views. Controls had greater activation than ME/CFS subjects with regard to ventral tegmental area (VTA), bilateral pedunculotegmental nuclei (L and R PTN, formerly pedunculopontine nuclei) and left parabrachial complex (L_PBC) by ANOVA with Tukey Honest Significant Difference $p<0.05$ (Table 3).

The only difference based on Orthostatic status on Day 1 was the greater L_PBC activation in POTS than STOPP (Table S7).

Males $(0.249 \pm 0.023$, mean $\pm 95 \% \mathrm{CI})$ showed a trend towards higher BOLD activation than females $(0.167 \pm 0.028, p=0.000012$ by unpaired two-tailed $t$-test $)$ when all nodes and subjects were assessed. The difference was significant for L_PO ( $p=0.046)$ (Table S8).

On the postexercise day, the relationship between groups became inverted as the control $(0.254 \pm 0.035$, mean $\pm 95 \% \mathrm{CI})$ and ME/CFS $(0.260 \pm 0.034)$ groups had significantly greater BOLD than GWI subjects by ANOVA when all subjects and nodes were evaluated $\left(p<10^{-9}\right.$ by two-tailed unpaired $t$-test with Bonferroni correction). After exertion, the control group was higher in bilateral MRF, VTA and R_PTN than GWI, while ME/CFS subjects had greater midline PAG, DR and MR and right MRF, LC and PBC than GWI ones (Table 4) (Figure 3). 
Table 3. ANOVA for pre-exercise differences based on disease status. BOLD signals for SC and GWI were numerically and statistically higher than ME/CFS (mean $\pm 95 \% \mathrm{CI}$, Tukey Honest Significant Difference, HSD). L and R indicate left and right, respectively. Hedges' g.

\begin{tabular}{|c|c|c|c|c|c|}
\hline & Control & ME/CFS & GWI & Control > ME/CFS & GWI > ME/CFS \\
\hline L_MRF & $0.266 \pm 0.164$ & $0.123 \pm 0.124$ & $0.197 \pm 0.103$ & & \\
\hline R_MRF & $0.331 \pm 0.181$ & $0.216 \pm 0.119$ & $0.172 \pm 0.103$ & & \\
\hline PAG & $0.234 \pm 0.145$ & $0.061 \pm 0.101$ & $0.222 \pm 0.089$ & & \\
\hline VTA & $0.279 \pm 0.127$ & $0.103 \pm 0.089$ & $0.193 \pm 0.061$ & $p=0.034, \mathrm{~g}=0.58$ & \\
\hline DR & $0.275 \pm 0.118$ & $0.086 \pm 0.103$ & $0.233 \pm 0.081$ & & \\
\hline MR & $0.295 \pm 0.124$ & $0.131 \pm 0.123$ & $0.249 \pm 0.087$ & & \\
\hline L_PO & $0.263 \pm 0.134$ & $0.061 \pm 0.126$ & $0.257 \pm 0.078$ & & $p=0.019, g=0.56$ \\
\hline R_PO & $0.290 \pm 0.134$ & $0.103 \pm 0.136$ & $0.252 \pm 0.087$ & & \\
\hline L_PTN & $0.316 \pm 0.133$ & $0.049 \pm 0.101$ & $0.264 \pm 0.086$ & $p=0.008, \mathrm{~g}=0.81$ & $p=0.009, \mathrm{~g}=0.60$ \\
\hline R_PTN & $0.356 \pm 0.126$ & $0.125 \pm 0.086$ & $0.259 \pm 0.080$ & $p=0.014, g=0.78$ & \\
\hline L_LC & $0.309 \pm 0.147$ & $0.142 \pm 0.158$ & $0.226 \pm 0.103$ & & \\
\hline R_LC & $0.316 \pm 0.181$ & $0.143 \pm 0.175$ & $0.274 \pm 0.126$ & & \\
\hline L_PBC & $0.331 \pm 0.139$ & $0.078 \pm 0.135$ & $0.231 \pm 0.092$ & $p=0.029, \mathrm{~g}=0.65$ & \\
\hline R_PBC & $0.299 \pm 0.148$ & $0.088 \pm 0.136$ & $0.263 \pm 0.101$ & & \\
\hline
\end{tabular}

Table 4. ANOVA for postexercise by disease status. Control and ME/CFS had significantly higher BOLD than GWI for several nodes. There was a general trend for GWI to have the lowest values in all regions. Mean $\pm 95 \%$ CI. Tukey Honest Significant Difference. Hedges' g.

\begin{tabular}{cccccc}
\hline & Control & ME/CFS & GWI & Control > GWI & ME/CFS > GWI \\
\hline N & 31 & 36 & 78 & & \\
L_MRF & $0.341 \pm 0.146$ & $0.206 \pm 0.147$ & $0.073 \pm 0.094$ & $p=0.008, \mathrm{~g}=0.65$ & \\
R_MRF & $0.364 \pm 0.149$ & $0.301 \pm 0.138$ & $0.077 \pm 0.084$ & $p=0.002, \mathrm{~g}=0.75$ & $p=0.014, \mathrm{~g}=0.58$ \\
PAG & $0.182 \pm 0.141$ & $0.271 \pm 0.142$ & $0.060 \pm 0.078$ & & $p=0.016, \mathrm{~g}=0.57$ \\
VTA & $0.252 \pm 0.104$ & $0.195 \pm 0.099$ & $0.078 \pm 0.068$ & $p=0.018, \mathrm{~g}=0.58$ & $p=0.009, \mathrm{~g}=0.60$ \\
DR & $0.229 \pm 0.113$ & $0.265 \pm 0.126$ & $0.068 \pm 0.070$ & & $p=0.018, \mathrm{~g}=0.54$ \\
MR & $0.231 \pm 0.115$ & $0.285 \pm 0.139$ & $0.092 \pm 0.075$ & & \\
L_PO & $0.178 \pm 0.125$ & $0.241 \pm 0.141$ & $0.129 \pm 0.082$ & & \\
R_PO & $0.248 \pm 0.131$ & $0.255 \pm 0.135$ & $0.101 \pm 0.077$ & & \\
L_PTN & $0.233 \pm 0.124$ & $0.208 \pm 0.127$ & $0.093 \pm 0.084$ & & \\
R_PTN & $0.308 \pm 0.158$ & $0.289 \pm 0.104$ & $0.126 \pm 0.074$ & $p=0.04, \mathrm{~g}=0.50$ & \\
L_LC & $0.223 \pm 0.144$ & $0.274 \pm 0.146$ & $0.097 \pm 0.089$ & & \\
R_LC & $0.276 \pm 0.167$ & $0.313 \pm 0.150$ & $0.077 \pm 0.095$ & & \\
L_PBC & $0.250 \pm 0.133$ & $0.250 \pm 0.135$ & $0.106 \pm 0.091$ & & \\
R_PBC & $0.240 \pm 0.135$ & $0.289 \pm 0.139$ & $0.110 \pm 0.076$ & & \\
\end{tabular}

There were no significant differences based on Orthostatic status following exercise (Table S9).

Gender was not a significant covariate for any region post exercise (Table S10). However, there was a general trend for females $(0.123 \pm 0.028$, mean $\pm 95 \% \mathrm{CI})$ to have lower BOLD than males $(0.197 \pm 0.021, p=0.000032$ by two-tailed unpaired $t$-test $)$ when all nodes and subjects were compared.

$\triangle B O L D$ was positive in the ME/CFS group and negative in the GWI group, indicating the significant dynamic effects caused by exercise in these two diseases (Figure 4). ME/CFS had higher increments than GWI for all seed regions except MRF and L_LC (Table 5). There were no differences between groups defined by Orthostatic status or gender. 

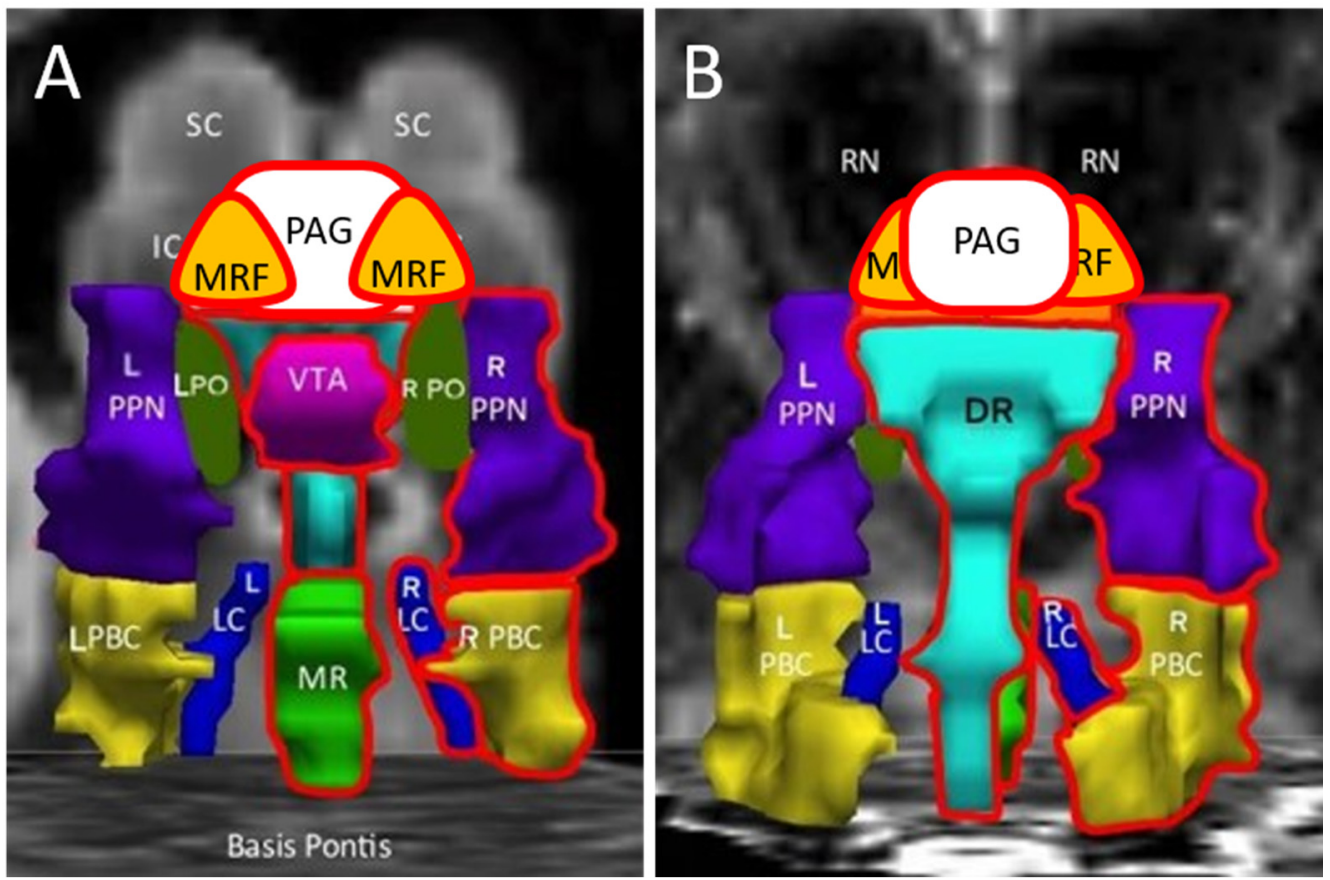

Figure 3. Post exercise. Anterior (A) and posterior (B) views indicate that GWI had significantly lower BOLD signals than control in the L_MRF, R_MRF, VTA and R_PTN (outlined in red, Tukey Honest Significant Difference, $p<0.05$ ) (Table 4). GWI was significantly lower in the R_MRF, PAG, DR, MR, R_PBC and R_LC than ME/CFS. There were no significant differences between the control and ME/CFS groups following exercise. Data are annotated as in Figure 1.

Table 5. $\triangle B O L D$. Exercise-induced changes in the 2-back $>0$-back condition were analyzed. Incremental changes $(\triangle B O L D=$ postexercise minus pre-exercise) were assessed by ANOVA then corrected for multiple comparisons with Tukey Honest Significant Difference. ME/CFS subjects had increased BOLD, while the GWI group had diminished BOLD after exercise. Control had no net change and was not statistically different from either of the other groups. Mean $\pm 95 \%$ CI. Hedges' g.

\begin{tabular}{ccccc}
\hline & SC & ME/CFS & GWI & ME/CFS > GWI \\
\hline N & 31 & 36 & 78 & \\
L_MRF $\Delta$ & $0.075 \pm 0.201$ & $0.083 \pm 0.163$ & $-0.124 \pm 0.129$ & \\
R_MRF $\Delta$ & $0.033 \pm 0.216$ & $0.085 \pm 0.171$ & $-0.095 \pm 0.122$ & $p=0.001, \mathrm{~g}=0.75$ \\
PAG & $-0.052 \pm 0.167$ & $0.210 \pm 0.175$ & $-0.162 \pm 0.110$ & $p=0.016, \mathrm{~g}=0.57$ \\
VTA $\Delta$ & $-0.027 \pm 0.138$ & $0.092 \pm 0.130$ & $-0.114 \pm 0.080$ & $p=0.001, \mathrm{~g}=0.75$ \\
DR & $-0.046 \pm 0.139$ & $0.179 \pm 0.159$ & $-0.165 \pm 0.103$ & $p=0.005, \mathrm{~g}=0.62$ \\
MR $\Delta$ & $-0.065 \pm 0.153$ & $0.155 \pm 0.173$ & $-0.157 \pm 0.113$ & $p=0.006, \mathrm{~g}=0.62$ \\
L_PO $\Delta$ & $-0.085 \pm 0.167$ & $0.180 \pm 0.181$ & $-0.128 \pm 0.108$ & $p=0.014, \mathrm{~g}=0.56$ \\
R_PO $\Delta$ & $-0.041 \pm 0.178$ & $0.152 \pm 0.175$ & $-0.151 \pm 0.123$ & $p=0.002, \mathrm{~g}=0.69$ \\
L_PTN $\Delta$ & $-0.083 \pm 0.154$ & $0.158 \pm 0.166$ & $-0.171 \pm 0.107$ & $p=0.004, \mathrm{~g}=0.66$ \\
R_PTN $\Delta$ & $-0.048 \pm 0.168$ & $0.164 \pm 0.155$ & $-0.132 \pm 0.100$ & \\
L_LC $\Delta$ & $-0.086 \pm 0.172$ & $0.133 \pm 0.201$ & $-0.129 \pm 0.130$ & $p=0.024, \mathrm{~g}=0.52$ \\
R_LC $\Delta$ & $-0.039 \pm 0.218$ & $0.169 \pm 0.220$ & $-0.197 \pm 0.165$ & $p=0.025, \mathrm{~g}=0.52$ \\
L_PBC $\Delta$ & $-0.081 \pm 0.181$ & $0.171 \pm 0.198$ & $-0.125 \pm 0.128$ & $p=0.005, \mathrm{~g}=0.62$ \\
R_PBC $\Delta$ & $-0.059 \pm 0.167$ & $0.202 \pm 0.195$ & $-0.153 \pm 0.129$ & \\
\hline
\end{tabular}



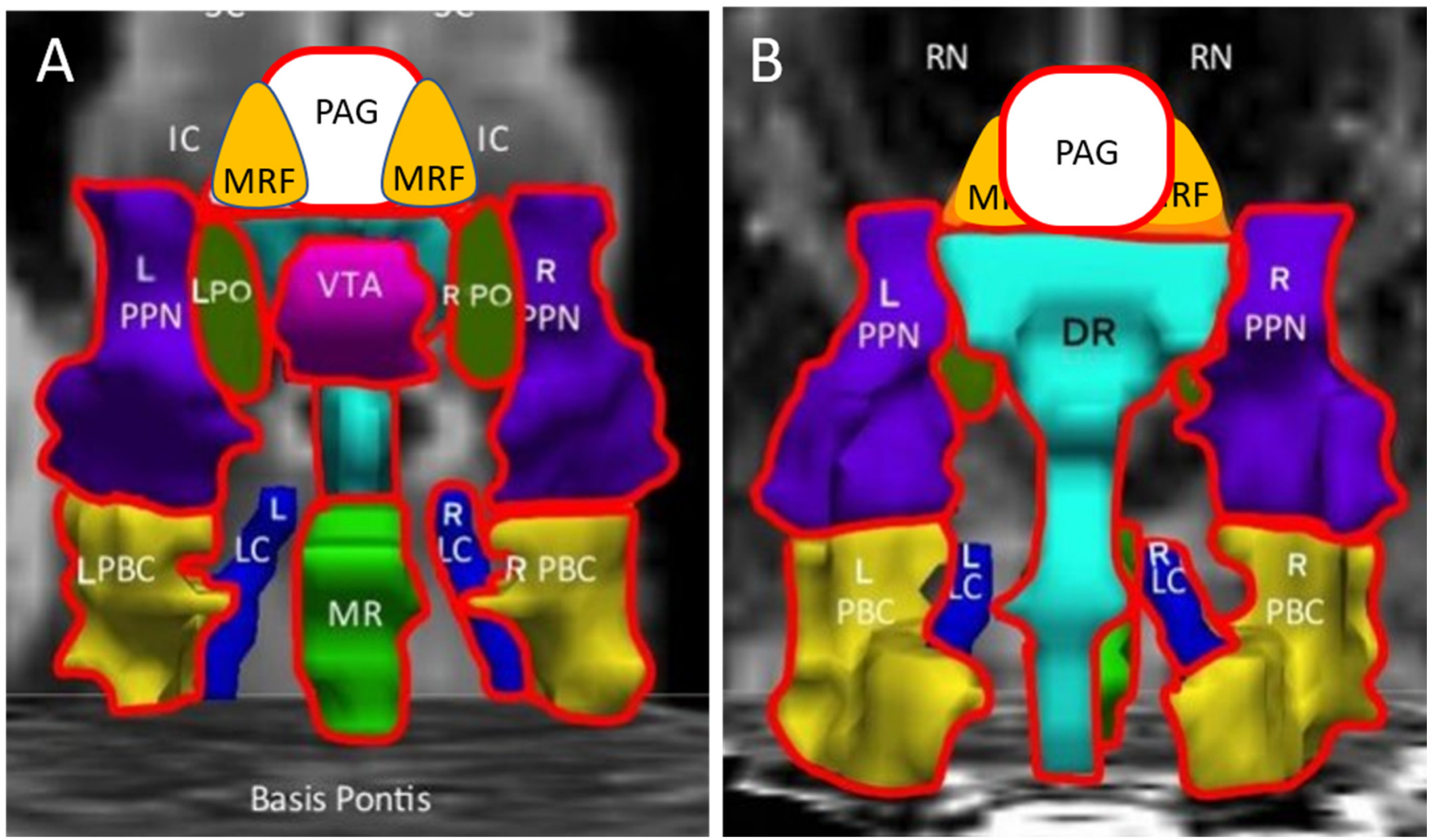

Figure 4. Exercise effects. Incremental changes $(\triangle \mathrm{BOLD})$ were significantly larger (more positive) for $\mathrm{ME} / \mathrm{CFS}$ than GWI (negative, diminished BOLD) in the midline PAG, VTA, DR and MR, bilateral PBC, PO and PTN, and R_LC (outlined in red) in the anterior (A) and posterior (B) views. Controls had no net changes. Data are from ANOVA analysis (Table 5).

\subsection{Multivariate General Linear Models (mGLM)}

The mGLM of pre-exercise data used Disease, orthostatic status, PTSD and gender as fixed factors with age, BMI and dolorimetry pressure thresholds as independent variables. Disease status was significant (Table S11). L_PTN activation was significantly lower in $\mathrm{ME} / \mathrm{CFS}$ subjects $(0.018 \pm 0.143$, mean $\pm 95 \% \mathrm{CI})$ than control $(0.326 \pm 0.198, p=0.047$ univariate significance) and GWI participants $(0.286 \pm 0.127, p=0.018)$ (Table S12). This was comparable to the ANOVA outcomes (Table 3). Orthostatic status was significant, with L_PBC being significantly lower in STOPP $(0.062 \pm 0.121$, mean $\pm 95 \%$ CI $)$ than POTS $(0.394 \pm 0.219, p=0.006$ Tukey Honest Significant Difference) and START $(0.397 \pm 0.164$, $p=0.034$ ) (Table S13). Age, gender, PTSD, BMI and dolorimetry pressure thresholds were not significant covariates prior to exercise.

Postexercise mGLM evaluated the same fixed factors and independent variables. Disease status was significant after exercise. ME/CFS and control participants had significantly higher BOLD activation than GWI in VTA, L_MRF and R_PTN (Table S14). Overall, ME/CFS was greater than GWI for all regions except L_PO, L_LC and L_PBC. More nodes were significant by mGLM than ANOVA (Table 4). Gender was significant for R_LC and R_PBC as males had greater BOLD activation than females after adjustment for the other variables (Table S15). Other significant interactions between disease, orthostatic and PTSD status, age and dolorimetry thresholds $(\mathrm{kg})$ were detailed in the Supplementary Online Material (Tables S16-S18), but must be interpreted with caution because of concerns about the number of variables, sample sizes and potential overfitting of the data.

Incremental changes in BOLD between days $(\triangle B \mathrm{BOL})$ reinforced the differences between diseases found by ANOVA (Table 5). The estimated marginal means for disease status, bracketed zero for controls, were positive for ME/CFS and negative for GWI (Table S19). 
Orthostatic status had a significant impact with higher activity for STOPP than START in R_LC $\Delta$ and bilateral PBC $\Delta$ (Table 6). The 95\% confidence intervals for POTS and STOPP bracketed zero, indicating no change after exercise. However, $\triangle B O L D$ was negative for the START group, indicating a dynamic exercise-induced effect on brainstem activation in this phenotype. Effect sizes were small, indicating that it may be difficult to reproduce the finding.

Table 6. Multivariate general linear model mGLM for $\triangle B O L D$ and orthostatic status. Estimated marginal means for incremental changes $(\triangle B O L D)$ were evaluated with disease and orthostatic status, PTSD and gender as fixed factors and age, BMI and dolorimetry as independent variables. The model was significant for disease status (Table S19) and orthostatic status (Wilks' Lambda = 0.651, $p=0.019$, Partial Eta Squared $=0.193$ ) but not age, gender, PTSD, BMI or dolorimetry. Additionally, 95\% confidence intervals for POTS and STOPP bracketed zero, indicating no net changes with exercise. The START phenotype was defined by exercise-induced postural tachycardia and had reduced BOLD activation in the R_LC and bilateral PBC following exercise. The STOPP phenotype was the normal condition with no change in postural tachycardia. Mean $\pm 95 \% \mathrm{CI}$. Univariate significance. Hedges' g.

\begin{tabular}{cccc}
\hline & POTS & START & STOPP \\
\hline L_MRF $\Delta$ & $-0.009 \pm 0.315$ & $-0.093 \pm 0.235$ & $-0.063 \pm 0.174$ \\
R_MRF & $0.003 \pm 0.319$ & $-0.096 \pm 0.239$ & $-0.051 \pm 0.177$ \\
PAG $\Delta$ & $0.004 \pm 0.271$ & $-0.140 \pm 0.202$ & $-0.026 \pm 0.150$ \\
VTA $\Delta$ & $-0.062 \pm 0.211$ & $-0.146 \pm 0.157$ & $0.034 \pm 0.116$ \\
DR $\Delta$ & $-0.090 \pm 0.251$ & $-0.153 \pm 0.188$ & $0.028 \pm 0.139$ \\
MR $\Delta$ & $-0.164 \pm 0.271$ & $-0.166 \pm 0.203$ & $0.050 \pm 0.150$ \\
L_PO $\Delta$ & $-0.085 \pm 0.274$ & $-0.170 \pm 0.204$ & $0.061 \pm 0.151$ \\
R_PO $\Delta$ & $-0.048 \pm 0.298$ & $-0.259 \pm 0.222$ & $0.072 \pm 0.164$ \\
L_PTN & $-0.247 \pm 0.256$ & $-0.098 \pm 0.191$ & $-0.028 \pm 0.142$ \\
R_PTN $\Delta$ & $-0.053 \pm 0.260$ & $-0.098 \pm 0.194$ & $-0.008 \pm 0.144$ \\
L_LC $\Delta$ & $-0.219 \pm 0.314$ & $-0.232 \pm 0.235$ & $0.102 \pm 0.174$ \\
R_LC $\Delta$ & $-0.070 \pm 0.390$ & $-0.329 \pm 0.291$ & $0.156 \pm 0.216$ \\
L_PBC $\Delta$ & $-0.304 \pm 0.302$ & $-0.268 \pm 0.226$ & $0.117 \pm 0.167$ \\
R_PBC $\Delta$ & $0.020 \pm 0.316$ & $-0.298 \pm 0.236$ & $0.110 \pm 0.174$ \\
\hline
\end{tabular}

\subsection{Light and Sound Sensitivity}

Provocations with light and sound showed that sensory sensitivities were significantly worse in ME/CFS and GWI than control subjects before and after exercise (Figure 5). A frequency analysis of light sensitivity prior to exercise found scores of 0 or 1 out of 20 (no discomfort) in $83.3 \%$ of SC, $30.8 \%$ of ME/CFS and $21.1 \%$ of GWI groups. Exercise worsened light sensitivity in paired analysis for the CFS $\left(p=2.7 \times 10^{-6}\right)$ and GWI groups $(p=0.022)$, and sound sensitivity in the ME/CFS $(p=0.037)$ group by 2-tailed paired $t$-tests. The incremental changes $(\Delta)$ were significantly larger in the ME/CFS group than the GWI and control groups ( $p<0.044$ by 2-tailed unpaired $t$-tests after Bonferroni corrections). Thresholds for significant sensitivities were $\geq 2$ out of 20 by receiver operating characteristics, indicating that visual and auditory hypersensitivity was common in the ME/CFS and GWI groups. The sound sensitivity and exaggerated startle responses were consistent with dysfunctional activity in the inferior colliculus [14]. 

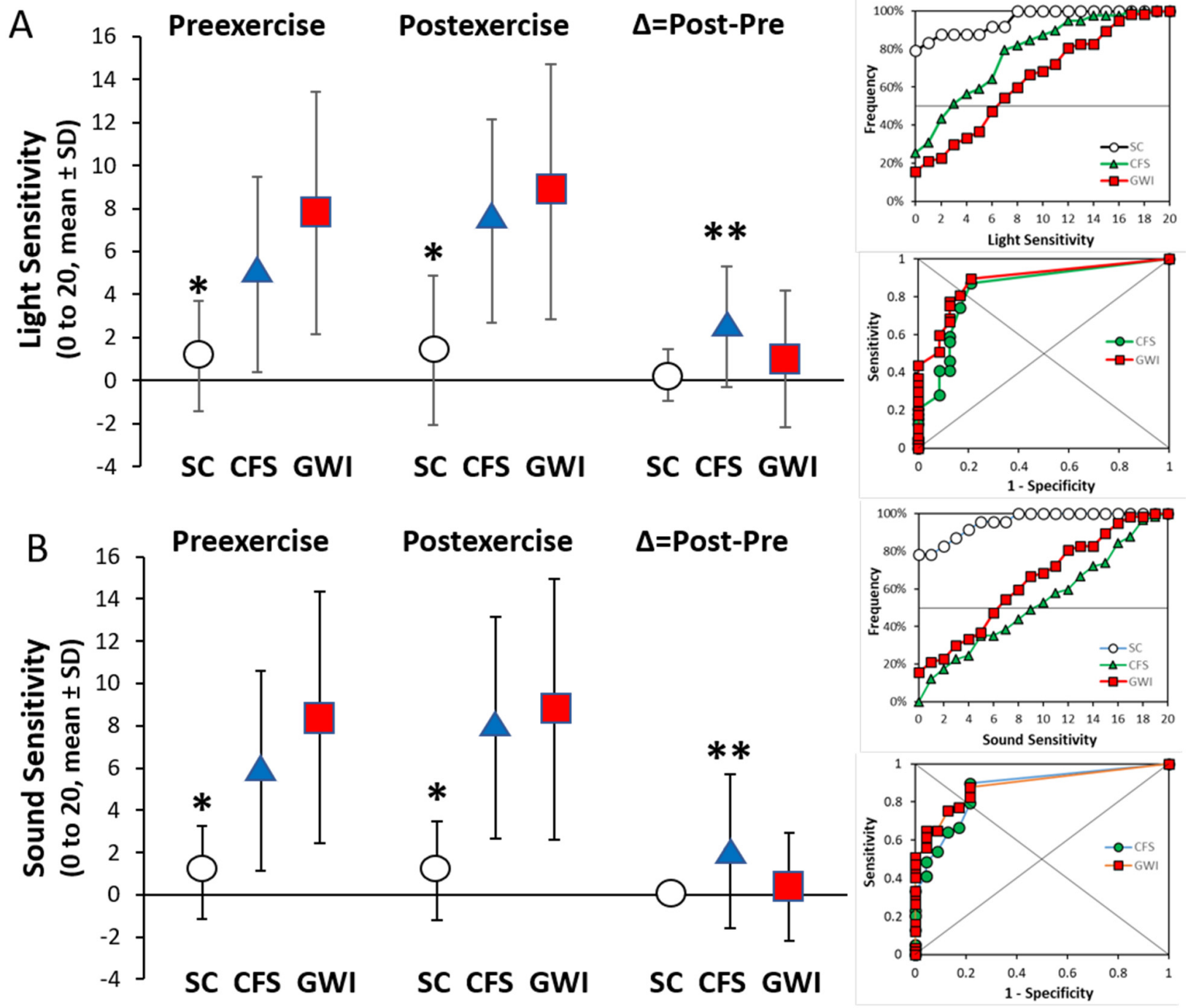

Figure 5. Light and sound sensitivity. Sensitivity was scored using modified Gracely box scores (range 0 to 20 points, mean $\pm \mathrm{SD}$ ). Light $(\mathbf{A})$ and sound (B) were significantly worse for ME/CFS (blue triangles) and GWI (red squares) than SC (white circles) before and after exercise $(* p<0.0001$ by 2-tailed unpaired $t$-test after Bonferroni correction). The incremental changes ( $\Delta=$ Post minus Pre) were larger in ME/CFS than SC and GWI (** $p<0.044$ by 2 -tailed unpaired $t$-tests after Bonferroni correction). Paired changes were significant for light and sound in the ME/CFS group, and light in GWI. Receiver operating characteristics (depicted on the right) defined light sensitivity as $\geq 2$ with $83.3 \%$ specificity and sensitivities of $74.4 \%$ for CFS and $80.7 \%$ for GWI (AUC $=0.884$ ). Sound sensitivity of $\geq 2$ had $78.3 \%$ specificity and sensitivities of $79.5 \%$ for ME/CFS and $82.5 \%$ for GWI $(\mathrm{AUC}=0.884)$.

\section{Discussion}

The BOLD data are the 2-back>0-back condition that contrasts the difficult highcognitive-load continuous 2-back working memory task against the simple low cognitive load 0-back stimulus matching attention task [14]. The postexercise and incremental data reflect the dynamic effects of exertion on cognition. Exercise caused changes in the 2-back $>0$-back condition that measures relative brain activation during the more difficult task. Specific effects on the 2-back alone, 0-back alone, and 0-back>2-back conditions were not assessed here.

The importance of the BOLD data is that there were differences in the relative levels of regional blood flow into midbrain nuclei. ME/CFS and GWI subjects had significant 
incremental changes following exercise whereas controls had no net changes. The changes seen in ME/CFS - and GWI subjects were antithetical to each other, indicating distinct dynamic exercise-induced pathological consequences.

In the original study [14], dorsal midbrain activation was not different between groups prior to exercise. A re-analysis of the same BOLD data using the ascending arousal network nuclei and seed region approach found baseline differences with lower BOLD in ME/CFS than control and GWI (Figure 2, Table 3). Controls had greater activation compared to ME/CFS in VTA, bilateral PTN and L PBC, while GWI subjects were higher than ME/CFS for left PTN and PO prior to exercise.

The pedunculotegmental nuclei (PTN) had reduced activation in ME/CFS. This cholinergic nucleus has extensive efferents that release acetylcholine throughout the cerebrum to maintain wakefulness and sustain attention. PTN assists in updating rapidly changing environmental information as required for our continuous 2-back task. Other functions and potential roles in disease dysfunction are discussed in the accompanying paper in this issue.

Exercise caused a significant dynamic switch in midbrain activation. Exercise caused an increase in BOLD in the ME/CFS group but a decrease in GWI subjects. Therefore, exercise had differential effects in the ME/CFS group compared to GWI subjects. Following exercise, the controls were greater than GWI subjects in VTA, bilateral MRF and right PTN, while the ME/CFS group was higher than GWI for midline PAG, DR and MR, and right lateral MRF, PBC and LC (Figure 3, Table 4). The seed region approach was consistent with the activation found in the original 141-voxel region of interest that also included inferior colliculus (Figure S1) [14]. All 141 voxels in the region of interest analysis were contiguous, but the seed region approach assayed the net activation within the smaller volumes defined by the seeds.

After exercise, the midline nuclei and MRF had significantly lower BOLD activation in GWI than the other two groups.

PAG is integral to threat assessment and instantaneous responses. The detection of a threat activates the PAG and midbrain reticular formation and causes a transition from relaxed wakefulness to high general attention [46]. Active responses range from freeze with conscious tonic immobility if motion would lead to detection by a nearby predator; a defensive approach to assess an ambiguous threat (modeled as rumination) [47,48]; flight via an escape route or shelter; and defensive attack if the predator is within a dangerous distance and escape is not possible [49,50].

VTA is a dopaminergic nucleus that stimulates the locus coeruleus to promote wakefulness [51,52]. It has a role in reward situations and positive emotion. Dysfunction is associated with anhedonia.

DR and MR are serotoninergic nuclei that project to the limbic system during active stress, conflicts and anxiety $[53,54]$. They may initiate fight or flight decisions. MR participates in tolerance and coping strategies with aversive stimuli as well as arousal, wakefulness and long-term memory.

In humans, the MRF is activated during the transition from a relaxed awake state to an attention-demanding state during reaction-time tasks [46] and during the focused investigation of threats while interpreting the proximity of danger (e.g., freezing in place) [55]. The caudal portion of the MRF extends into the cuneiform region, which is correlated with cardiovascular dysfunction in ME/CFS [56,57] and pontis oralis (PO).

The right locus coeruleus (R_LC) had significantly lower activation in GWI than $\mathrm{ME} / \mathrm{CFS}$ subjects after exercise $[58,59]$. This is the predominant source of noradrenergic innervation in the brain $[58,59]$. Integrated PAG, amygdala and sensory information activate the LC to generate diffuse efferent outputs to the cerebrum and brainstem [60]. They act in an instantaneous fashion like a tripwire for immediate instinctual responses such as freeze-fight-flight, focused cerebral attention and sympathetic activation for immediate action. Inappropriate or dysfunctional activation contributes to anxiety and PTSD [61]. Atrophy of the right locus coeruleus was found at autopsy in veterans with PTSD [62]. 
Exercise caused no incremental changes in controls ( $\triangle$ BOLD). However, exertion led to significant positive increments in ME/CFS and, by contrast, decreases in GWI. The dynamic changes were significantly different between ME/CFS and GWI for midline PAG, DR, MR and VTA, right LC, and bilateral PTN, PBC, and PO (Figure 4, Table 4). The opposite directions of change indicated that distinctly different pathological mechanisms that regulate midbrain blood flow and neurovascular coupling were modulated by exercise in the two diseases, indicating that ME/CFS and GWI were excellent "illness controls" for each other.

Both ME/CFS and GWI had significant light and sound sensitivity (Figure 4). These sensations are monitored in the superior and inferior colliculus, respectively. The inferior colliculi are innervated by the ascending hindbrain auditory pathway (the lateral lemniscus), somatosensory pathways from the medulla, pons, and arousal nuclei [63]. The inferior colliculus participates in multimodal sensory perceptions, vestibulo-ocular reflex, predator aversion and escape, prey localization, social communication, analgesia and fear-related behaviors. Sharp acoustic stimulation initiates the startle response with acutely accentuated attention and surveillance, leading to visual and truncal orientation towards the sound, generalized hyperarousal and aversive behaviors [64-67]. Inferior colliculus is relevant to the light and sound sensitivity and heightened startle response in ME/CFS, GWI and veterans with PTSD [68].

The inferior colliculus is highly metabolically active and vulnerable to toxic injury [63]. ME/CFS have reduced cerebral blood flow during heads up tilt [69] and exercise [70], which may reduce the oxygen supply to the susceptible inferior colliculus and lead to dorsal midbrain dysfunction. The exercise-induced lability of cerebral blood flow and neurovascular coupling may contribute to the dysfunctional BOLD patterns in the midbrain, insula and cerebellum vermis in the GWI and ME/CFS groups [14] but with different mechanisms and statistically reciprocal outcomes in the two diseases.

The general linear models assessed the relative influences and interactions between disease, orthostatic and gender status on each day and adjusted for age, PTSD, BMI and dolorimetry thresholds. Outcomes for disease status were generally comparable to the ANOVA results.

Orthostatic status was significant before exercise as START and POTS had higher BOLD than STOPP in the left PBC (Table S13). POTS had postural tachycardia before and after exercise, while START were defined by exercise-induced postural tachycardia $[26,27,31]$. After exercise, START underwent a dynamic incremental depression of BOLD activation in the R_LC and bilateral PBC (Table 4) compared to the STOPP subjects who had no changes in BOLD or postural heart rate. The involvement of the locus coeruleus in START implies exercise-induced autonomic dysfunction. The PBC interrogates pain and interoceptive visceral sensations then forwards the information to the PAG, thalamus, hypothalamus, and amygdala for further processing [71]. PBC is recruited in states of malaise as an adaptive component of the sickness response [72] and so may participate in the experience of postexertional malaise.

Hedges' $\mathrm{g}$ ranged from 0.50 to 0.81 for differences between groups by ANOVA (Tables 3-5), which suggests moderate-to-high effect sizes for replication of the significant results using the same protocols.

It is important to appreciate the limitations of these disease and exercise effects. The findings were inferred based on the seed regions extracted from the ascending arousal network. Coordinates of the seed regions may improve as newer standards are created [40]. The actual metric being compared is the 2-back $>0$-back differential activity during the difficult cognitive working memory task. The results may not be applicable to the resting state or other cognitive tasks. The neural and vascular responses combined to generate these data without providing insights into functional connectivity or molecular mechanisms. Brainstem motion may blur the borders of nuclei in this seed region approach. Therefore, we consider the results to be a general predictor of changes in BOLD for nuclei in the ascending arousal network that are congruent with the dorsal midbrain region of interest found in 
our previous study [14]. The results do suggest that significant differences will be found in future studies that specifically target these nuclei in ME/CFS and GWI when suitable sample sizes are compared and advanced motion correction algorithms are applied [73-76]. The most significant differences were induced by exercise with elevated BOLD in ME/CFS subjects but reductions in the GWI group, and were most clearly exposed by a comparison of ME/CFS vs. GWI groups rather than differences from control subjects (Table 5 and Table S19).

\section{Conclusions}

The seed region approach based on the ascending arousal network extended our previous finding of exercise-induced changes in BOLD during a high-cognitive-load 2-back working memory task. The salient findings were significantly lower BOLD in the midbrain at baseline in the ME/CFS group compared to the GWI and control groups, and significant dynamic changes after exercise with elevation of BOLD in ME/CFS subjects but a reduction in the GWI group. A review of the functions of midbrain nuclei provides a fresh perspective on potential neural pathologies affecting inferior colliculus (startle), oculomotor and visual systems, PAG, MRF and other nuclei for threat assessment, anxiety, negative emotion, pain and tenderness and other aspects of the ME/CFS and GWI clinical experiences. The data provide an initial framework to power future studies of postexertional malaise and midbrain dysfunction.

Supplementary Materials: The following supporting information can be downloaded at: https: / / www.mdpi.com/article/10.3390/brainsci12010078/s1, Figure S1: Midbrain Region of Interest; Table S1: Preexercise multivariate general linear modal for BOLD with self-reported demographics as independent variables; Table S2: Preexercise mGLM of demographic fixed factors. Orthostatic status, Low back pain (LBP), Depression, Heart disease, gender and Marital status were fixed factors with no other covariates; Table S3: Partial correlations between BOLD and questionnaire data; Table S4: Legend for significance of partial correlations for Table S3; Table S5: Partial correlations for Preexercise, Postexercise and Delta BOLD in the upper left corner of Table S3; Table S6: Partial correlations for subjective symptom severities in the lower right corner of Table S3; Table S7: Orthostatic status preexercise; Table S8: Gender status preexercise; Table S9: Postexercise orthostatic status; Table S10: Postexercise gender status; Table S11: Preexercise model; Table S12: Disease status in preexercise mGLM; Table S13: Orthostatic status in preexercise mGLM; Table S14: Disease status in postexercise mGLM; Table S15: Gender in postexercise mGLM; Table S16: Postexercise regression analysis; Table S17: Postexercise multivariate general linear model for Disease status based on regression analysis (Table S16); Table S18: Postexercise multivariate general linear model for gender based on regression analysis (Table S14); Table S19: Estimated marginal means for $\triangle B O L D$ and Disease status.

Author Contributions: J.N.B. obtained funding, conducted the clinical study, supervised data collection and analysis and prepared the manuscript. A.A. and H.P. performed statistical analysis. S.D.W. analyzed fMRI data. All authors have read and agreed to the published version of the manuscript.

Funding: We have no direct or indirect financial, institutional, or personal conflicts of interest to report.

Institutional Review Board Statement: The study was conducted according to the guidelines of the Declaration of Helsinki and approved by the Institutional Review Board (or Ethics Committee) of GEORGETOWN UNIVERSITY 2013-0943, 2015-0579, 2009-229, 29 June 2021, and Department of Defense Human Research Protection Office Log Number A-18749, 16 September 2019.

Informed Consent Statement: Informed consent was obtained from all subjects involved in the study.

Data Availability Statement: Primary data are attached in Supplementary Materials.

Acknowledgments: The study was supported by funding from The Sergeant Sullivan Circle, Barbara Cottone, Dean Clarke Bridge Prize, Department of Defense Congressionally Directed Medical Research Program (CDMRP) W81XWH-15-1-0679 and W81-XWH-09-1-0526, and the National Institute of Neurological Disorders and Stroke R21NS088138 and RO1NS085131. This project has been funded 
in whole or in part with Federal funds (Grant \#UL1TR000101 previously UL1RR031975) from the National Center for Advancing Translational Sciences (NCATS), National Institutes of Health (NIH), through the Clinical and Translational Science Awards Program (CTSA), a trademark of DHHS, part of the Roadmap Initiative, "Re-Engineering the Clinical Research Enterprise".

Conflicts of Interest: The authors declare that the research was conducted in the absence of any commercial or financial relationships that could be construed as a potential conflict of interest. Funding agencies had no influence on the research or manuscript.

\section{References}

1. Fukuda, K.; Straus, S.E.; Hickie, I.; Sharpe, M.C. The Chronic Fatigue Syndrome: A Comprehensive Approach to Its Definition and Study. Ann. Intern. Med. 1994, 121, 953-959. [CrossRef]

2. $\quad$ Carruthers, B.M.; Jain, A.K.; De Meirleir, K.L.; Peterson, D.L.; Klimas, N.G.; Lerner, A.M.; Bested, A.C.; Flor-Henry, P.; Joshi, P.; Powles, A.P.; et al. Myalgic Encephalomyelitis/Chronic Fatigue Syndrome. J. Chronic Fatigue Syndr. 2003, 11, 7-115. [CrossRef]

3. Fukuda, K.; Nisenbaum, R.; Stewart, G.; Thompson, W.W.; Robin, L.; Washko, R.M.; Noah, D.L.; Barrett, D.H.; Randall, B.; Herwaldt, B.L.; et al. Chronic multisymptom illness affecting Air Force veterans of the Gulf War. J. Am. Med. Assoc. 1998, 280, 981-988. [CrossRef]

4. Steele, L. Prevalence and patterns of Gulf War illness in Kansas veterans: Association of symptoms with characteristics of person, place, and time of military service. Am. J. Epidemiol. 2000, 152, 992-1002. [CrossRef] [PubMed]

5. $\quad$ Daugherty, S.A.; Henry, B.E.; Peterson, D.L.; Swarts, R.L.; Bastien, S.; Thomas, R.S. Chronic Fatigue Syndrome in Northern Nevada. Clin. Infect. Dis. 1991, 13, S39-S44. [CrossRef] [PubMed]

6. Friedberg, F.; Bateman, L.; Bested, A.; Davenport, T.; Friedman, K.; Gurwitt, A.; Jason, L.; Lappp, C.; Stevens, S.; Underhill, R.; et al Me/CFS: Primer for Clinical Practitioners; International Association for Chronic Fatigue Syndrome/Myalgic Encephalomyelitis: Stony Brook, NY, USA, 2014; pp. 1-541.

7. Lim, E.-J.; Ahn, Y.-C.; Jang, E.-S.; Lee, S.-W.; Lee, S.-H.; Son, C.-G. Systematic review and meta-analysis of the prevalence of chronic fatigue syndrome/myalgic encephalomyelitis (CFS/ME). J. Transl. Med. 2020, 18, 100. [CrossRef]

8. Committee on the Diagnostic Criteria for Myalgic Encephalomyelitis/Chronic Fatigue Syndrome; Board on the Health of Select Populations; Institute of Medicine. Beyond Myalgic Encephalomyelitis/Chronic Fatigue Syndrome: Redefining an Illness; National Academies Press: Washington, DC, USA, 2015; ISBN 0309316898.

9. White, R.F.; Steele, L.; O'Callaghan, J.P.; Sullivan, K.; Binns, J.H.; Golomb, B.A.; Bloom, F.E.; Bunker, J.A.; Crawford, F.; Graves, J.C.; et al. Recent research on Gulf War illness and other health problems in veterans of the 1991 Gulf War: Effects of toxicant exposures during deployment. Cortex 2016, 74, 449-475. [CrossRef] [PubMed]

10. Steele, L.; Sastre, A.; Gerkovich, M.M.; Cook, M.R. Complex Factors in the Etiology of Gulf War Illness: Wartime Exposures and Risk Factors in Veteran Subgroups. Environ. Health Perspect. 2012, 120, 112-118. [CrossRef]

11. Johnson, M.K. Organophosphorus esters causing delayed neurotoxic effects: Mechanism of action and structure activity studies Arch. Toxicol. 1975, 34, 259-288. [CrossRef] [PubMed]

12. Namba, T.; Nolte, C.T.; Jackrel, J.; Grob, D. Poisoning due to organophosphate insecticides. Acute and chronic manifestations Am. J. Med. 1971, 50, 475-492. [CrossRef]

13. Richardson, R.J.; Fink, J.K.; Glynn, P.; Hufnagel, R.B.; Makhaeva, G.F.; Wijeyesakere, S.J. Neuropathy target esterase (NTE/PNPLA6) and organophosphorus compound-induced delayed neurotoxicity (OPIDN). Adv. Neurotoxic. 2020, 4,1-78. [CrossRef]

14. Washington, S.D.; Rayhan, R.U.; Garner, R.; Provenzano, D.; Zajur, K.; Addiego, F.M.; VanMeter, J.W.; Baraniuk, J.N. Exercise alters brain activation in Gulf War Illness and Myalgic Encephalomyelitis/Chronic Fatigue Syndrome. Brain Commun. 2020, 2, fcaa070. [CrossRef]

15. Stouten, B. Identification of ambiguities in the 1994 chronic fatigue syndrome research case definition and recommendations for resolution. BMC Health Serv. Res. 2005, 5, 3-5. [CrossRef]

16. Jones, J.F.; Lin, J.-M.S.; Maloney, E.M.; Boneva, R.S.; Nater, U.M.; Unger, E.R.; Reeves, W.C. An evaluation of exclusionary medical/psychiatric conditions in the definition of chronic fatigue syndrome. BMC Med. 2009, 7, 57. [CrossRef] [PubMed]

17. Nater, U.M.; Lin, J.M.S.; Maloney, E.M.; Jones, J.F.; Hao, T.; Boneva, R.S.; Raison, C.L.; Reeves, M.W.C.; Heim, C. Psychiatric comorbidity in persons with chronic fatigue syndrome identified from the georgia population. Psychosom. Med. 2009, 71,557-565. [CrossRef]

18. American Psychiatric Association. Diagnostic and Statistical Manual of Mental Disorders; American Psychiatric Association: Washington, DC, USA, 2013; ISBN 0-89042-555-8.

19. Spitzer, R.L.; Kroenke, K.; Williams, J.B. Validation and utility of a self-report version of PRIME-MD: The PHQ primary care study. Primary Care Evaluation of Mental Disorders. Patient Health Questionnaire. JAMA 1999, 282, 1737-1744. [CrossRef]

20. Baraniuk, J.N.; Adewuyi, O.; Merck, S.J.; Ali, M.; Ravindran, M.K.; Timbol, C.R.; Rayhan, R.; Zheng, Y.; Le, U.; Esteitie, R.; et al. A Chronic Fatigue Syndrome (CFS) severity score based on case designation criteria. Am. J. Transl. Res. 2013, 5, 53-68.

21. McHorney, C.A.; Ware, J.E.; Rachel Lu, J.F.; Sherbourne, C.D. The MOS 36-ltem Short-Form Health Survey (SF-36): III. Tests of Data Quality, Scaling Assumptions, and Reliability across Diverse Patient Groups. Med. Care 1994, 32, 40-66. [CrossRef] 
22. Cella, M.; Chalder, T. Measuring fatigue in clinical and community settings. J. Psychosom. Res. 2010, 69, 17-22. [CrossRef]

23. Dworkin, R.H.; Turk, D.C.; Revicki, D.A.; Harding, G.; Coyne, K.S.; Peirce-Sandner, S.; Bhagwat, D.; Everton, D.; Burke, L.B.; Cowan, P.; et al. Development and initial validation of an expanded and revised version of the Short-form McGill Pain Questionnaire (SF-MPQ-2). Pain 2009, 144, 35-42. [CrossRef]

24. Naranch, K.; Park, Y.-J.; Repka-Ramirez, M.S.; Velarde, A.; Clauw, D.; Baraniuk, J.N. A Tender Sinus does not Always Mean Rhinosinusitis. Otolaryngol. Neck Surg. 2002, 127, 387-397. [CrossRef]

25. Surian, A.A.; Baraniuk, J.N. Systemic Hyperalgesia in Females with Gulf War Illness, Chronic Fatigue Syndrome and Fibromyalgia. Sci. Rep. 2020, 10, 5751. [CrossRef]

26. Garner, R.; Baraniuk, J.N. Orthostatic intolerance in chronic fatigue syndrome. J. Transl. Med. 2019, 17, 185. [CrossRef]

27. Garner, R.S.; Rayhan, R.U.; Baraniuk, J.N. Verification of exercise-induced transient postural tachycardia phenotype in Gulf War Illness. Am. J. Transl. Res. 2018, 10, 3254-3264.

28. Gracely, R.H.; Kwilosz, D.M. The Descriptor Differential Scale: Applying psychophysical principles to clinical pain assessment. Pain 1988, 35, 279-288. [CrossRef]

29. Rayhan, R.U.; Washington, S.D.; Garner, R.; Zajur, K.; Martinez Addiego, F.; Vanmeter, J.W.; Baraniuk, J.N. Exercise challenge alters Default Mode Network dynamics in Gulf War Illness. BMC Neurosci. 2019, 20, 7. [CrossRef]

30. Washington, S.D.; Rayhan, R.U.; Garner, R.; Provenzano, D.; Zajur, K.; Addiego, F.M.; VanMeter, J.W.; Baraniuk, J.N. Exercise alters cerebellar and cortical activity related to working memory in phenotypes of Gulf War Illness. Brain Commun. 2020, 2, fcz039. [CrossRef] [PubMed]

31. Rayhan, R.U.; Stevens, B.W.; Raksit, M.P.; Ripple, J.A.; Timbol, C.R.; Adewuyi, O.; VanMeter, J.W.; Baraniuk, J.N. Exercise Challenge in Gulf War Illness Reveals Two Subgroups with Altered Brain Structure and Function. PLoS ONE 2013, 8, e63903. [CrossRef]

32. Friston, K.J.; Williams, S.; Howard, R.; Frackowiak, R.S.; Turner, R. Movement-related effects in fMRI time-series. Magn. Reson. Med. 1996, 35, 346-355. [CrossRef]

33. Whitfield-Gabrieli, S.; Nieto-Castanon, A. Conn: A functional connectivity toolbox for correlated and anticorrelated brain networks. Brain Connect. 2012, 2, 125-141. [CrossRef]

34. Evans, A.C.; Collins, D.L.; Mills, S.R.; Brown, E.D.; Kelly, R.L.; Peters, T.M. 3D statistical neuroanatomical models from 305 MRI volumes. In Proceedings of the 1993 IEEE Conference Record Nuclear Science Symposium and Medical Imaging Conference, San Francisco, CA, USA, 31 October-6 November 1993; pp. 1813-1817.

35. SPM12 Software-Statistical Parametric Mapping. Available online: https://www.fil.ion.ucl.ac.uk/spm/software/spm12/ (accessed on 16 February 2021).

36. Edlow, B.L.; Takahashi, E.; Wu, O.; Benner, T.; Dai, G.; Bu, L.; Grant, P.E.; Greer, D.M.; Greenberg, S.M.; Kinney, H.C.; et al. Neuroanatomic connectivity of the human ascending arousal system critical to consciousness and its disorders. J. Neuropathol. Exp. Neurol. 2012, 71, 531-546. [CrossRef] [PubMed]

37. Athinoula, A. Martinos Center for Biomedical Imaging. Harvard Ascending Arousal Network Atlas. Available online: https: / / www.nmr.mgh.harvard.edu/resources/aan-atlas (accessed on 1 February 2020).

38. Horn, A.; Kühn, A.A. Lead-DBS: A toolbox for deep brain stimulation electrode localizations and visualizations. Neuroimage 2015, 107, 127-135. [CrossRef]

39. Horn, A.; Li, N.; Dembek, T.A.; Kappel, A.; Boulay, C.; Ewert, S.; Tietze, A.; Husch, A.; Perera, T.; Neumann, W.-J.; et al. Lead-DBS v2: Towards a comprehensive pipeline for deep brain stimulation imaging. Neuroimage 2019, 184, 293-316. [CrossRef] [PubMed]

40. Nowacki, A.; Nguyen, T.A.-K.; Tinkhauser, G.; Petermann, K.; Debove, I.; Wiest, R.; Pollo, C. Accuracy of different threedimensional subcortical human brain atlases for DBS -lead localisation. NeuroImage. Clin. 2018, 20, 868-874. [CrossRef] [PubMed]

41. Brett, M. Region of interest analysis using an SPM toolbox. Neuroimage 2002, 13, $210-217$.

42. Brett, M. MarsBaR region of interest toolbox for SPM. Neuroimage 2002, 16, 769-1198.

43. Puelles, L. Comments on the limits and internal structure of the mammalian midbrain. Anatomy 2016, 10, 60-70. [CrossRef]

44. Puelles, L. Survey of Midbrain, Diencephalon, and Hypothalamus Neuroanatomic Terms Whose Prosomeric Definition Conflicts with Columnar Tradition. Front. Neuroanat. 2019, 13, 20. [CrossRef] [PubMed]

45. Watson, C.; Bartholomaeus, C.; Puelles, L. Time for Radical Changes in Brain Stem Nomenclature-Applying the Lessons from Developmental Gene Patterns. Front. Neuroanat. 2019, 13, 10. [CrossRef]

46. Kinomura, S.; Larsson, J.; Gulyás, B.; Roland, P.E. Activation by attention of the human reticular formation and thalamic intralaminar nuclei. Science 1996, 271, 512-515. [CrossRef]

47. Blanchard, D.C.; Griebel, G.; Pobbe, R.; Blanchard, R.J. Risk assessment as an evolved threat detection and analysis process. Neurosci. Biobehav. Rev. 2011, 35, 991-998. [CrossRef] [PubMed]

48. Blanchard, D.C. Translating dynamic defense patterns from rodents to people. Neurosci. Biobehav. Rev. 2017, 76, 22-28. [CrossRef]

49. Bracha, H.S. Freeze, flight, fight, fright, faint: Adaptationist perspectives on the acute stress response spectrum. CNS Spectr. 2004, 9, 679-685. [CrossRef]

50. Hashemi, M.M.; Gladwin, T.E.; de Valk, N.M.; Zhang, W.; Kaldewaij, R.; van Ast, V.; Koch, S.B.J.; Klumpers, F.; Roelofs, K. Neural Dynamics of Shooting Decisions and the Switch from Freeze to Fight. Sci. Rep. 2019, 9, 4240. [CrossRef] [PubMed]

51. Morales, M.; Margolis, E.B. Ventral tegmental area: Cellular heterogeneity, connectivity and behaviour. Nat. Rev. Neurosci. 2017, 18, 73-85. [CrossRef]

52. Ranaldi, R. Dopamine and reward seeking: The role of ventral tegmental area. Rev. Neurosci. 2014, 25, 621-630. [CrossRef] 
53. Michelsen, K.A.; Prickaerts, J.; Steinbusch, H.W.M. The dorsal raphe nucleus and serotonin: Implications for neuroplasticity linked to major depression and Alzheimer's disease. Prog. Brain Res. 2008, 172, 233-264. [CrossRef] [PubMed]

54. Paul, E.D.; Lowry, C.A. Functional topography of serotonergic systems supports the Deakin/Graeff hypothesis of anxiety and affective disorders. J. Psychopharmacol. 2013, 27, 1090-1106. [CrossRef]

55. Mobbs, D.; Petrovic, P.; Marchant, J.L.; Hassabis, D.; Weiskopf, N.; Seymour, B.; Dolan, R.J.; Frith, C.D. When Fear Is Near: Threat Imminence Elicits Prefrontal-Periaqueductal Gray Shifts in Humans. Science 2007, 317, 1079-1083. [CrossRef]

56. Barnden, L.R.; Shan, Z.Y.; Staines, D.R.; Marshall-Gradisnik, S.; Finegan, K.; Ireland, T.; Bhuta, S. Hyperintense sensorimotor T1 spin echo MRI is associated with brainstem abnormality in chronic fatigue syndrome. NeuroImage Clin. 2018, 20, 102-109. [CrossRef]

57. Barnden, L.R.; Kwiatek, R.; Crouch, B.; Burnet, R.; Del Fante, P. Autonomic correlations with MRI are abnormal in the brainstem vasomotor centre in Chronic Fatigue Syndrome. NeuroImage Clin. 2016, 11, 530-537. [CrossRef] [PubMed]

58. Morris, L.S.; McCall, J.G.; Charney, D.S.; Murrough, J.W. The role of the locus coeruleus in the generation of pathological anxiety. Brain Neurosci. Adv. 2020, 4, 2398212820930321. [CrossRef]

59. Samuels, E.R.; Szabadi, E. Functional neuroanatomy of the noradrenergic locus coeruleus: Its roles in the regulation of arousal and autonomic function part II: Physiological and pharmacological manipulations and pathological alterations of locus coeruleus activity in humans. Curr. Neuropharmacol. 2008, 6, 254-285. [CrossRef] [PubMed]

60. De Cicco, V.; Tramonti Fantozzi, M.P.; Cataldo, E.; Barresi, M.; Bruschini, L.; Faraguna, U.; Manzoni, D. Trigeminal, Visceral and Vestibular Inputs May Improve Cognitive Functions by Acting through the Locus Coeruleus and the Ascending Reticular Activating System: A New Hypothesis. Front. Neuroanat. 2017, 11, 130. [CrossRef]

61. Naegeli, C.; Zeffiro, T.; Piccirelli, M.; Jaillard, A.; Weilenmann, A.; Hassanpour, K.; Schick, M.; Rufer, M.; Orr, S.P.; Mueller-Pfeiffer, C. Locus Coeruleus Activity Mediates Hyperresponsiveness in Posttraumatic Stress Disorder. Biol. Psychiatry 2018, 83, 254-262. [CrossRef] [PubMed]

62. Bracha, H.S. Postmortem Locus Coeruleus Neuron Count in Three American Veterans with Probable or Possible War-Related PTSD. J. Neuropsychiatr. 2005, 17, 503-509. [CrossRef] [PubMed]

63. Bordia, T.; Zahr, N.M. The Inferior Colliculus in Alcoholism and Beyond. Front. Syst. Neurosci. 2020, 14, 606345. [CrossRef]

64. Brandão, M.L.; Melo, L.L.; Cardoso, S.H. Mechanisms of defense in the inferior colliculus. Behav. Brain Res. 1993, 58, 49-55. [CrossRef]

65. Parham, K.; Willott, J.F. Effects of inferior colliculus lesions on the acoustic startle response. Behav. Neurosci. 1990, 104, 831-840. [CrossRef]

66. Heeringa, A.N.; van Dijk, P. The immediate effects of acoustic trauma on excitation and inhibition in the inferior colliculus: A Wiener-kernel analysis. Hearth Res. 2016, 331, 47-56. [CrossRef]

67. Xiong, B.; Alkharabsheh, A.; Manohar, S.; Chen, G.-D.; Yu, N.; Zhao, X.; Salvi, R.; Sun, W. Hyperexcitability of inferior colliculus and acoustic startle reflex with age-related hearing loss. Hearth Res. 2017, 350, 32-42. [CrossRef]

68. Orr, S.P.; Lasko, N.B.; Shalev, A.Y.; Pitman, R.K. Physiologic responses to loud tones in Vietnam veterans with posttraumatic stress disorder. J. Abnorm. Psychol. 1995, 104, 75-82. [CrossRef]

69. van Campen, C.L.M.C.; Verheugt, F.W.A.; Rowe, P.C.; Visser, F.C. Cerebral blood flow is reduced in ME/CFS during head-up tilt testing even in the absence of hypotension or tachycardia: A quantitative, controlled study using Doppler echography. Clin. Neurophysiol. Pract. 2020, 5, 50-58. [CrossRef] [PubMed]

70. Patrick Neary, J.; Roberts, A.D.W.; Leavins, N.; Harrison, M.F.; Croll, J.C.; Sexsmith, J.R. Prefrontal cortex oxygenation during incremental exercise in chronic fatigue syndrome. Clin. Physiol. Funct. Imaging 2008, 28, 364-372. [CrossRef] [PubMed]

71. Chiang, M.C.; Bowen, A.; Schier, L.A.; Tupone, D.; Uddin, O.; Heinricher, M.M. Parabrachial Complex: A Hub for Pain and Aversion. J. Neurosci. 2019, 39, 8225-8230. [CrossRef] [PubMed]

72. Kelley, K.W.; Bluthé, R.-M.; Dantzer, R.; Zhou, J.-H.; Shen, W.-H.; Johnson, R.W.; Broussard, S.R. Cytokine-induced sickness behavior. Brain. Behav. Immun. 2003, 17 (Suppl. S1), S112-S118. [CrossRef]

73. Satterthwaite, T.D.; Ciric, R.; Roalf, D.R.; Davatzikos, C.; Bassett, D.S.; Wolf, D.H. Motion artifact in studies of functional connectivity: Characteristics and mitigation strategies. Hum. Brain Mapp. 2019, 40, 2033-2051. [CrossRef]

74. Parkes, L.; Fulcher, B.; Yücel, M.; Fornito, A. An evaluation of the efficacy, reliability, and sensitivity of motion correction strategies for resting-state functional MRI. Neuroimage 2018, 171, 415-436. [CrossRef]

75. Terem, I.; Dang, L.; Champagne, A.; Abderezaei, J.; Pionteck, A.; Almadan, Z.; Lydon, A.-M.; Kurt, M.; Scadeng, M.; Holdsworth, S.J. 3D amplified MRI (aMRI). Magn. Reson. Med. 2021, 86, 1674-1686. [CrossRef] [PubMed]

76. VanElzakker, M.B.; Brumfield, S.A.; Lara Mejia, P.S. Neuroinflammation and Cytokines in Myalgic Encephalomyelitis/Chronic Fatigue Syndrome (ME/CFS): A Critical Review of Research Methods. Front. Neurol. 2018, 9, 1033. [CrossRef] [PubMed] 